\title{
A SAÚde EM TEMPOS DE DESENVOLVIMENTO: A CAMPANHA DE ERRADICAÇÃO DA MALÁRIA NA AMAZÔNIA
}

\author{
HEALTH In DEVELOPMENT TIMES: THE MALARIA ERADICATION \\ CAMPAIGN IN THE AMAZON
}

\author{
Rômulo De Paula Andrade* \\ romulopa@hotmail.com
}

\begin{abstract}
RESUMO: Nas décadas de 1950 e 1960, uma descoberta feita pelo médico Mario Pinotti ganhou vulto no Brasil e no mundo: a mistura de um antimalárico (cloroquina) ao sal de cozinha, dando origem ao chamado sal cloroquinado. O método de controle e erradicação da malária foi pensado e aplicado em uma região na qual a doença era (e ainda é) endêmica: a Amazônia. $O$ artigo trata de três momentos específicos: as pesquisas iniciais que legitimaram a aplicação do produto em larga escala; a Campanha de Erradicação de Malária na região amazônica e, por fim, o ocaso do chamado sal medicamentoso como ferramenta de controle da doença. Por meio da articulação entre ciência, saúde e desenvolvimento, pretende-se aqui compreender este período da história da Amazônia.
\end{abstract}

PalavRAS-ChaVe: História das Ciências, História da Saúde Pública, História da Amazônia.

ABSTRACT: In the 1950s and 1960s, a discovery made by the doctor Mario Pinotti was successful in Brazil and in the world: a mixture of chloroquine with table salt. The method of control and eradication of malaria was designed and implemented in a region where the disease was (and still is) endemic: the Amazon. The article deals with three specific stages: the initial research that legitimized aplication of the product on a large scale; Malaria Eradication Campaign in the Amazon region and, ultimately, the decline of the call Pinotti salt as disease control tool. Through the link between science, health and development, it is intended here to understand this period of history of the Amazon

KEYWORDS: History of Science, History of Public Health, History of Amazon.

\section{O duende da Amazônia nos anos do Desenvolvimento}

O presente artigo trata de um episódio específico na longa história de combate à doença que mais atinge a Amazônia e seus habitantes: a malária. No curso do texto, serão privilegiados os testes, aplicação, ascensão e queda de um método criado pelo brasileiro Mario Pinotti para o controle da doença: a mistura de sal de cozinha com um antimalárico, a cloroquina, nos anos 1950 e 1960. Durante um curto tempo, o chamado "sal Pinotti" foi

\footnotetext{
* Doutorado em História das Ciências pela Casa de Oswaldo Cruz/FioCruz. Pesquisador em História das Ciências e da Saúde do Departamento de Pesquisa (DEPES) da Casa de Oswaldo Cruz/Fundação Oswaldo Cruz.
} 
utilizado pela Organização Mundial da Saúde para a Campanha de Erradicação da Malária em diversas regiões do mundo. Como a bibliografia sustenta, muito do prestígio do novo método de controle da enfermidade estava relacionado ao lugar que o Pinotti se situava na sociedade daqueles anos: diretor do Serviço Nacional de Malária e, posteriormente, ministro da saúde de Juscelino Kubitschek. O escopo do presente texto é a região amazônica e forma pela qual o sal cloroquinado foi utilizado pelos médicos e pela publicidade da época como ferramenta de desenvolvimento e integração de um local historicamente caracterizado como periférico. Inicialmente, será privilegiada a malária e seu lugar no imaginário social da Amazônia para a seguir, verticalizarmos nossa análise no processo envolvendo os testes e aplicação do método Pinotti.

A malária é uma doença causada pelo protozoário plasmodium, que é transmitido para os seres humanos por meio dos mosquitos infectados do gênero Anopheles, e sempre foi uma das principais causas de mortalidade na Amazônia. Seu nome vem do italiano mala (mal) aria (ar), termo do século XVII referente às febres intermitentes de que os doentes sofriam (consideravam que a doença era fruto da exposição aos "maus ares") (DUNN, 2003). Mais do que apenas uma enfermidade, a malária também foi causadora de uma série de estigmas recorrentes sobre os habitantes da Amazônia, como "indolentes" e "não afeitos ao trabalho". De acordo com Rosenberg, a malária é uma enfermidade multifatorial, pois sua incidência é relacionada às complexas interdependências entre as circunstâncias sociais, econômicas e ambientais de um local (ROSENBERG, 2007)

A doença, de acordo com Djalma Batista, não é natural da região, mas encontrou lá terreno propício para sua proliferação. O mesmo processo teria ocorrido com o seu principal vetor, o Anopheles Gambiae, trazido pelo Vale do Açu pelas lanchas da Air France, que faziam o correio de Dakar a Natal nos anos de 1930 (BATISTA, 1976). No início do século XX, começou-se a pensar a malária como uma doença causadora do atraso econômico da região. Vários planos de ação foram pensados, mas a execução, normalmente falha e com pouca continuidade, nunca solucionou tais problemas. As campanhas feitas por diferentes governos brasileiros no curso do século XX conseguiram extinguir a doença em quase todo o território nacional, menos na Amazônia, responsável por quase a totalidade da incidência da doença no país (CIVES, 2012). Não à toa, o médico Oswaldo Cruz, em seu relatório sobre as doenças na região no início do século XX, chamava a malária de "duende da Amazônia", por constituir tanto um mistério que acompanhava a mítica região, como uma realidade que desafiava os mais confiantes cientistas (SCHWEICKARDT, 2009).

Nos anos 1950, as concepções e políticas de saúde no país relacionavam-se com o "otimismo sanitário" que prevaleceu no mundo nas duas décadas posteriores. Isto foi devido a disponibilidade de novos recursos e tecnologias (inseticidas, antibióticos e antimaláricos), 
que davam impulso aos projetos governamentais e de agências bilaterais de cooperação formulados para implementar programas que visavam a controlar e erradicar doenças do chamado mundo subdesenvolvido. Um dos desafios centrais seria romper com o chamado "círculo vicioso da pobreza", preconizado por Gunnar Myrdal em 1952. Nesse contexto, surge uma contribuição brasileira para a luta contra a malária: a adição de cloroquina (um dos antimaláricos mais utilizados) ao sal utilizado nas residências. A inspiração para esta ideia foi a iodetação do sal, pensada para dar fim à grande incidência do bócio endêmico no país. Assim, o sal de cozinha foi considerado o melhor instrumento para superar esses desafios da saúde pública e transformou-se em elemento central de tais projetos (HOCHMAN, 2010).

Duas doenças completamente diferentes convergiam diante de um mesmo objetivo: o controle e a consequente erradicação com os recursos médicos disponíveis, com os desafios presentes naquele momento: a vastidão territorial do país, a dificuldade de acesso a certas áreas, e, por fim, a pobreza de grande parte da população rural e urbana (IDEM). Proposta desde os anos 1940, a obrigatoriedade da iodetação do sal só se tornou efetiva em meados da década de 1970, demorando três décadas para ser implantado de fato em escala nacional. Já, por outro lado, inspirados no sal iodado, os malariologistas brasileiros propuseram, em 1953, a distribuição gratuita de sal de cozinha misturado com cloroquina, então o antimalárico mais utilizado. Diferente do caso do iodo, o sal cloroquinado começou a ser testado em 1952 e tornou-se política nacional em 1959, passando a integrar também o Programa de Erradicação de Malária da Organização Mundial da Saúde.

Hochman e Silva (2011) associam a ascensão e queda do novo método de controle da malária à ascensão e queda de seu criador, Mário Pinotti, que, desde 1942, ocupava o cargo máximo no Serviço Nacional de Malária (SNM). Em menos de uma década, o Método Pinotti foi formulado, testado e celebrado como uma inovação brasileira, além de ter reconhecimento internacional, passando a integrar estratégias de luta contra a malária. 0 rápido reconhecimento do Sal Pinotti relacionou-se diretamente relacionado aos programas de desenvolvimento criados nos anos 1950, que visavam a superar as endemias rurais, recuperando, assim, a população do interior do Brasil para o trabalho rural e incorporando as áreas afetadas a projetos de modernização de agricultura (IDEM).1

O malariologista ganhou vulto a partir do resultado positivo dede seus trabalhos: a redução drástica da malária no início da década de 1950 em várias regiões do país, que foi celebrada como resultado de novas descobertas da ciência (inseticidas de ação residual e antimaláricos) e uma conquista do sanitarismo brasileiro associado ao dirigente máximo da SNM. Suas pesquisas por novas ferramentas de combate à enfermidade relacionam-se à 
busca de cientistas daquela época por alternativas ao método mais utilizado nas campanhas pelo mundo: o uso do Dicloro-Difenil-Tricloroetano, ou como ficou mais conhecido, o DDT. Inicialmente desenvolvido pela empresa suíça Gelgy para controlar uma epidemia de tifo, o DDT se tornou rapidamente, após a Segunda Guerra Mundial, rotineiro na vida, na saúde pública e na agricultura (CAMPOS, 2006).1 O DDT teve grande impacto em países que contavam com condições sanitárias desenvolvidas, fazendo com que o mosquito transmissor não tivesse condições de desenvolver nichos ecológicos e alternativos para a reprodução.

No Brasil, a partir do sucesso na campanha no estado Rio de Janeiro, a utilização em larga escala do DDT transformou-se em modelo de ação para o resto do país, obtendo bons resultados no controle da enfermidade. Mas sua eficácia não era a mesma em áreas de difícil localização, razão pela qual os malariologistas brasileiros buscavam outra alternativa. Por isso, foi proposta a distribuição gratuita do sal de cozinha cloroquinado como método complementar para a ação de inseticidas. Um dos grandes desafios para os malariologistas era a malária endêmica na região amazônica, caracterizada na época como uma localidade onde vivia uma população dispersa, com áreas de difícil acesso, residências precárias; acresce-se a isso, o fato de o mosquito transmissor apresentar hábitos silvestres que dificultam o uso do inseticida nas casas e abrigos. Não à toa, regiões do estado do Pará e do Maranhão, zonas endêmicas de malária, foram utilizadas como teste para provar a eficácia do novo medicamento. Além disso, foram feitas experiências com doentes hospitalizados para verificação da dose diária de cloroquina necessária para debelar o acesso febril de malária e eliminar os parasitas do sangue periférico dos pacientes.

\section{Os testes no Pará e no Maranhão}

Entre junho de 1952 e maio de 1953, o Serviço Nacional de Malária levou a cabo uma pesquisa de campo na região do Rio Capim, no Pará, para testar a eficácia do sal cloroquinado. A equipe foi liderada pelo entomologista Reginaldo Damasceno, quadro do SNM e colaborador de Pinotti em artigos. O Serviço, por sua vez, emprestou aos funcionários uma lancha para transporte do sal e abrigo dos funcionários designados para colaborar no trabalho. A região fora escolhida para realizar a experiência pelas seguintes razões: índice parasitário satisfatório na ocasião do início das experiências com o sal; alta infestação do vetor da malária; alto preço cobrado no comércio local pelos antimaláricos, o que praticamente impossibilitava ou reduzia a doses insuficientes a medicação dos habitantes. Outro fator levado em consideração para a escolha foi o predomínio de alimentação fresca (caça e pesca) pelos habitantes, o que demonstrava, para os técnicos do SNM, que a 
população local faria a ingestão regular do sal cloroquinado nas doses diárias previstas. Basicamente, nota-se que os pesquisadores estavam em busca de locais ermos, nos quais a utilização do DDT seria inviável ou impossível, ou seja, lugares miseráveis por excelência. Prova disso é que outras regiões também pesquisadas (rio Cupijoca, em Cametá e vila do Acarí, às margens do Guamá) foram excluídas da experiência, pois tinham índices parasitários relativamente baixos, unidades distribuidoras de antimaláricos funcionando perfeitamente e a predominância de alimentação naturalmente salgada (charque, pirarucu), prejudicando a ingestão regular de sal.

Através de entrevistas, os pesquisadores descobriram que a população do Rio Capim e suas habitações nunca tinham sido protegidas por inseticidas de ação residual, transformando a região em um objeto de estudo praticamente "ideal" (SNM, 1952). A prova disso era o fato de, em nenhuma das casas visitadas, terem sido encontradas fichas de aplicação de DDT. O abastecimento do sal comum no comércio local era feito por uma embarcação motorizada, a única que fazia linha na região, ou era adquirido diretamente na sede do município e transportado pelos próprios comerciantes em embarcações a vela ou remo. $\mathrm{O}$ argumento dos pesquisadores era de que, devido a este limitado transporte, 0 controle do produto seria melhor. As condições de vida da população eram as piores possíveis: as crianças e mulheres empregavam-se na agricultura da mandioca para o preparo da farinha e os homens dedicavam-se à extração da madeira e do comércio de animais silvestres. As próprias habitações tornavam os habitantes nômades. Durante a inundação dos rios no inverno amazônida (janeiro a abril), a população se retirava para os barrancos, para que, logo que o período de chuvas cessasse, voltassem para as margens. No período de experiências, os pesquisadores contavam que algumas famílias tiveram que se mudar até cinco vezes no período de dez meses. Desta forma, seria impossível usar o DDT diante destas condições. Um ponto crucial para o teste do medicamento na região do Rio Capim era que o consumo de sal na região era elevado, pois devido à distância entre o comércio e os habitantes e a abundância de caça e peixe, a população sempre estocava uma quantidade regular de sal em casa (IDEM).

A distribuição do sal medicamentoso no comércio era feita pelo sistema de permuta: recolhiam o sal comum para ser cloroquinado e davam em troca o produto pronto; já nas habitações, os agentes recolhiam todo o sal comum existente e davam a mesma quantidade em troca. Com os dados do relatório, é impossível imaginar como foi o contato dos pesquisadores com a população. Algumas dúvidas cabem: a população e o comércio aceitaram passivamente a "troca" do sal? Ocorreu alguma resistência? Infelizmente não possuímos tais informações, mas a partir da análise dos relatórios é possível inferir alguns pontos. Durante quase um ano, foram distribuídos 10.977 quilos de sal cloroquinado, 
positivados em 2.065 amostras de sangue. Por fim, os pesquisadores conseguiram comprovar que o uso regular do sal reduzia a quantidade de plasmódios no sangue a índices muito baixos, demonstrando assim o sucesso da experiência (DAMASCENO, 1953). Em julho de 1953, uma nova comissão de estudos foi ao Maranhão, em busca de municípios que constituiriam "tipos ideais" para os testes com o sal cloroquinado. Liderados por Ramon Affoso Anhel, chefe do Setor Maranhão do SNM, escolheram duas localidades que pertenciam a São Luís (capital), cujo único acesso possível era de barco à vela: Aracaji, com população total de 90 habitantes, e Guarapiranga, que contava com 40 habitantes (ANHEL, 1953).

\section{Imagem 1:}

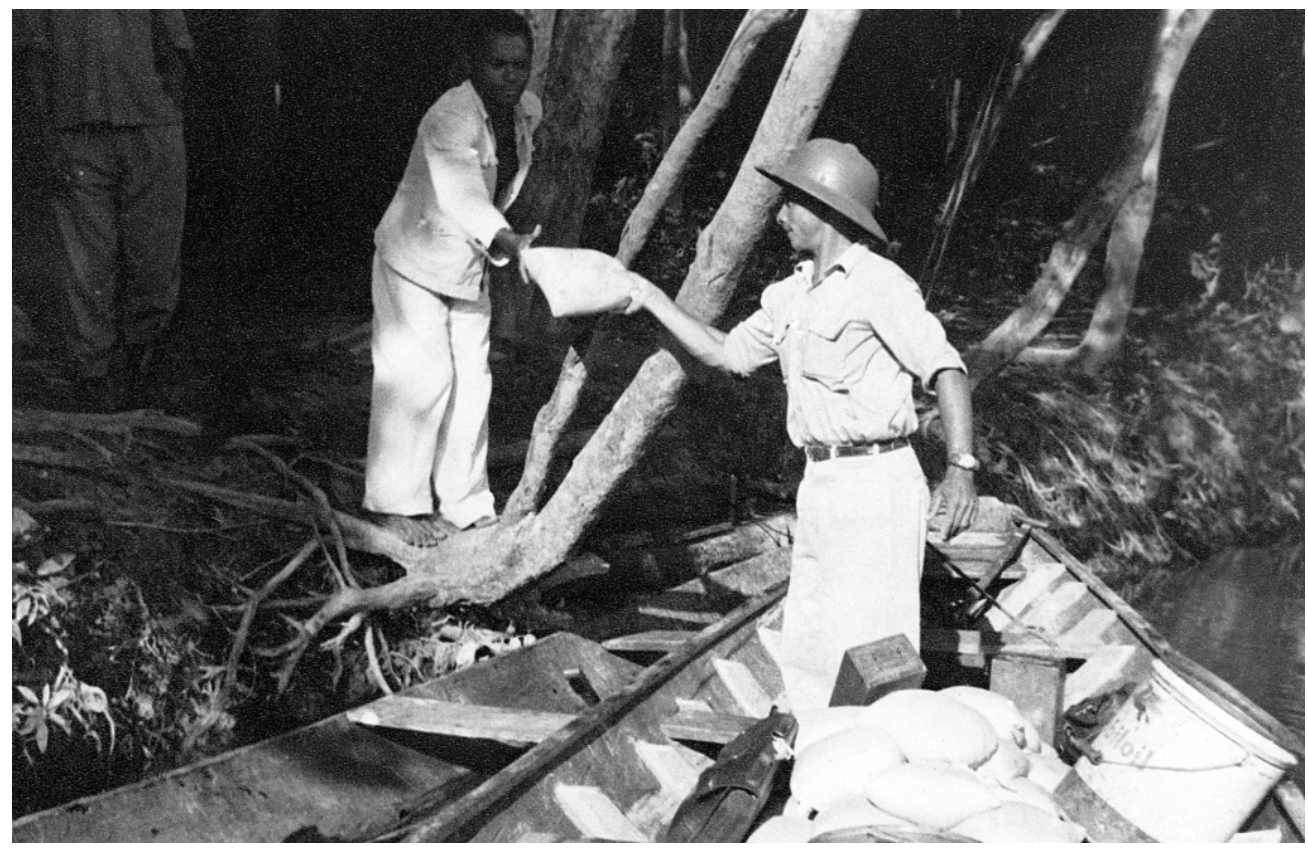

Distribuição de Sal Cloroquinado na Região Amazônica [1952-1955].

Fundo Rostan Soares, Fot.01

Assim como a região do Rio Capim, seria possível controlar o acesso dos habitantes a remédios, pois só existia em Aracaji e Guarapiranga um único comerciante responsável pela distribuição de sal para a região. Mas por estarem próximos da capital, poderiam conseguir de alguma forma acesso aos centros de distribuição de medicamentos que lá existiam. Desta forma, para evitar a aquisição dos medicamentos, a equipe fechou a unidade distribuidora mais próxima das duas comunidades, praticamente impossibilitando o acesso da população (IDEM). Diante de pedidos insistentes, distribuíram comprimidos de cálcio e sulfas para acalmar os ânimos dos locais. Mesmo diante de tanto controle os moradores dos vilarejos conseguiram adquirir os remédios. Por dedicarem-se à pesca, faziam migrações diárias e acabavam adquirindo os remédios em outras localidades pelo mar, conseguindo 
também, inclusive, a compra dos medicamentos na capital, São Luís. Mesmo apontando estes percalços, Anhel constatou que "não restava dúvida" quanto à eficiência do método, pois em ambas as localidades, a contagem dos plasmódios no sangue dos habitantes baixou de $18,6 \%$ para zero nos 60 dias de trabalho (IDEM).

Os resultados positivos impulsionaram Pinotti a publicar artigos divulgando sua nova descoberta científica. O malariologista publicou no periódico oficial do SNM sua palestra no XI Congresso Brasileiro de Higiene, ocorrido em novembro de 1953 - ou seja, pouco tempo depois da aplicação dos trabalhos de campo no Pará e no Maranhão. Na comunicação, Pinotti destacava os benefícios que o controle de malária tinha trazido ao país até aquele momento, dando conta da drástica diminuição do total de vítimas da doença, redução estimada em 95\% (PINOTTI, 1954). Desta forma, o controle doméstico e a aplicação do DDT no litoral continuariam trazendo diminuições nos números de enfermos. Porém, para se atingir a erradicação da doença seria necessário lançar mão de novas metodologias, como a distribuição de sal cloroquinado, considerada pelo malariologista como a melhor forma de se atingir o interior do país, em especial nos locais que contavam com habitação precária, o que fazia com que o mosquito transmissor se abrigasse fora da casa das pessoas. Em locais como a Amazônia, que contava com densidade demográfica reduzida e áreas quase inacessíveis, o controle pelo DDT tornar-se-ia extremamente custoso, além de ineficaz. Por isso a união entre o sal de cozinha e a cloroquina poderia se transformar em uma alternativa mais barata e efetiva para se atingir todos os rincões do Brasil. Pinotti indicava o sal cloroquinado para eliminar o resíduo de malária mantido por transmissão extradomiciliária e, eventualmente, para substituir o DDT em áreas com malária transmitidas por anofelinos que não frequentassem as habitações (IDEM). Desta forma, o sal cloroquinado seria uma "arma preciosa" que seria usada como complemento do DDT.

Como forma de divulgar as pesquisas do malariologista para um público mais amplo, foi lançado o documentário intitulado Malária no Inferno Verde, produzido pela Jean Manzon Films. Neste filmete de cerca de seis minutos, é demonstrado, pelo ponto de vista da ciência, a forma de retirar a Amazônia, nas palavras dos políticos da época, do triste posto de ser um dos locais mais subdesenvolvidos no Brasil. Jean Manzon, dono da produtora, era conhecido fotógrafo da revista $O$ Cruzeiro, que, devido a sua influência junto aos políticos da época, passou a elaborar cinejornais e documentários por demanda.1 Provavelmente o filmete foi feito sob encomenda do Serviço Nacional de Malária, tal o protagonismo das ações do serviço e de seu diretor no cinejornal. Bizzelo (1995) caracterizou os documentários da Jean Manzon Films como curta metragens de prestação de serviços orientados para a promoção e a venda de informação positiva. De acordo com a pesquisadora, o cliente, em primeiro lugar, definia o "espírito", ou seja, o objetivo e a mensagem do filme. Sem seu aval, 
a montagem não prosseguia. A ele eram submetidas a primeira versão, para depois serem feitas as modificações sugeridas. Os documentários eram exibidos normalmente antes de a sessão cinematográfica começar. Não é possível afirmar se o Malária No Inferno Verde foi amplamente veiculado no cinema, mas estas pistas dão conta de que o filmete serviu para, ao menos, reafirmar o prestígio de Mario Pinotti e confirmar sua ascensão nos quadros políticos da época. Desta forma, o dirigente do SNM aliava pesquisa científica ao próprio projeto político, delineando uma trajetória semelhante à de muitos homens de ciência do século XX.1

Com a narração de Luiz Jatobá (conhecido pela apresentação do Repórter Esso), e com texto do poeta Paulo Mendes Campos, o documentário mostra, sob um plano aéreo, Mario Pinotti sobrevoando a Amazônia brasileira e os trabalhos de distribuição do sal cloroquinado na região. $O$ texto reforça vários clichês sobre a Amazônia, apresentando o sal cloroquinado como uma ferramenta da ciência para integrá-la ao Brasil ("Estes Brasileiros só agora estão sentindo que pertencem ao Brasil"). A região é caracterizada a partir da idéias oriundas de romances, como Inferno Verde, de Alberto Rangel. Utilizando uma retórica também vista no Estado Novo (1937-1945), a região é caracterizada como insalubre e despovoada, onde a chave para o reencontro da Amazônia com seu destino heróico estaria na aplicação do sal cloroquinado.

Há no documentário o imperativo do saneamento e a conquista definitiva da Amazônia, uma retórica bastante utilizada por governos anteriores.1 De acordo com o documentário, graças ao SNM e ao sal cloroquinado, os homens da região estariam sendo tirados de seu abandono. Como Hochman (2010) destaca, o uso do sal cloroquinado só se dá de forma extensiva a partir de 1959, mas pelas imagens divulgadas no filme, percebe-se a intenção de aumentar a abrangência do uso do produto, como se fosse aplicado em toda a região amazônica. Até o momento do documentário (1954), o medicamento tinha sido testado apenas em localidades de baixa densidade demográfica do Maranhão e do Pará. De qualquer forma, a retórica divulgada no documentário era de que o SNM, liderado por Pinotti, estava integrando a Amazônia definitivamente ao país:

Qualquer trabalho na Amazônia é duro, penoso e sacrificado. Tudo é arrancado da natureza pelo braço do homem. O homem denodado da Amazônia luta contra o clima, as águas, as feras, a distância, a solidão e as febres. Seu lar é a mata virgem, povoada de perigos e de mistérios. (...) As vanguardas do serviço nacional de malária penetraram na Amazônia, num posto avançado na floresta. Preparam-se armas defensivas contra a malária. Embarcações de toda a espécie distribuem o sal cloroquinado. 0 maior trabalho, porém, na complicada geografia da Amazônia é a sua 
distribuição entre a população rarefeita e dispersa. E o sal deve chegar, custe o que custar! Para recuperar o brasileiro da Amazônia! Não existem dificuldades! Os modestos servidores do Serviço de Malária são um admirável exemplo de dedicação e sacrifício! Nas florestas e rios da Amazônia, desconhecem repouso. Arriscam a vida, expõem a saúde para levar aos irmãos distantes defesa e proteção contra o mal. São os soldados desconhecidos de uma grande batalha que se trava no perigo e na aspereza das selvas. (MANZON, 1954)

Um indício que serve de base para a relação entre a ascensão do sal e o prestígio de Pinotti é o fato de o medicamento, mesmo ainda em fase experimental, já fazer parte de projetos de saúde governamentais. O Primeiro Plano Qüinqüenal da Superintendência de Valorização Econômica da Amazônia, publicado em 1955, continha as metas que os diferentes setores da agência deveriam atingir. O setor saúde do documento já direcionava grande parte das ações referentes ao combate à malária para o sal cloroquinado e o colocava como prioridade no plano de ação para a Amazônia. Segundo a subcomissão de saúde, a inclusão do novo medicamento tinha ocorrido por sugestão do SNM. O projeto ainda dedicava atenção ao uso extensivo do DDT e destacava que o órgão "ensaiava" um novo método de combate à doença, que, mesmo em estágio de experimentação, já gozava de prestígio junto à comunidade científica brasileira (BRASIL, 1955). Mesmo em fase de testes, algumas questões já teriam sido resolvidas, como o paladar, a resistência do produto à degradação e o modo de distribuição, com emprego do disfofato de cloroquina, que já era uma das armas por excelência distribuídas pelas unidades de distribuição. Como a maior parte do sal consumido pelos estados do Amazonas, Pará, Território do Acre e Amapá era distribuída no porto de Belém e de Manaus, deixando o controle da entrega do sal mais fácil, somente essas regiões ficariam compreendidas na campanha de uso do novo medicamento. Passaria à responsabilidade do SNM escolher, entre esses lugares, as áreas indicadas para emprego exclusivo do uso de sal cloroquinado, suspendendo-se, desta forma, a dedetização domiciliar (IDEM). 
Imagem 2:

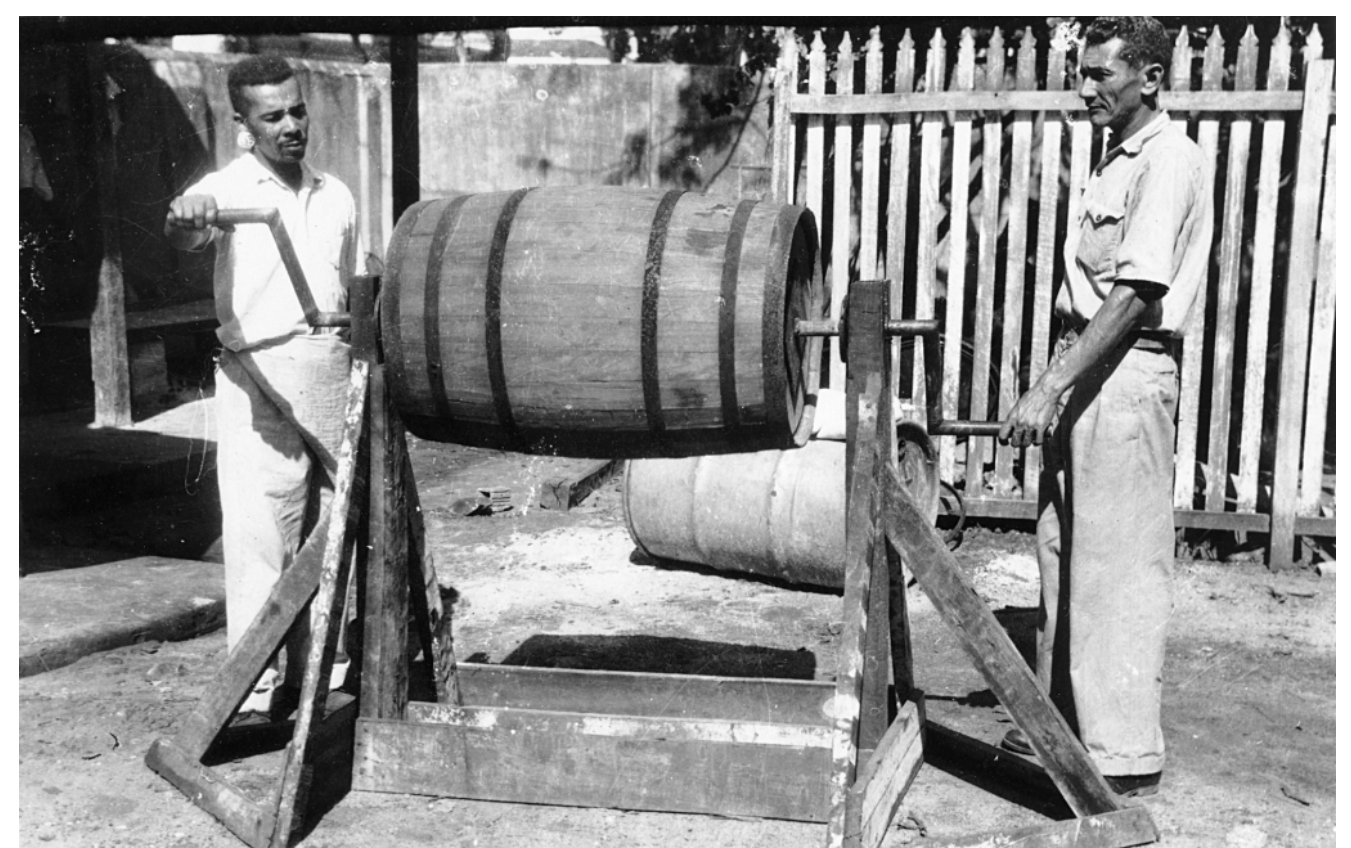

Preparação do Sal Cloroquinado. Região Amazônica [1952-1955].

Fundo Rostan Soares, fot.29.

Assim, o chamado "Método Pinotti" angariava cada vez mais prestígio no país. Em 1955, com a divulgação dos resultados dos trabalhos de campo no Maranhão, no Pará e no Paraná, reforçou-se a certeza de que o plano funcionaria (PINOTTI, 1955). O sucesso do método também atingia nível internacional, quando alcançou expressiva repercussão em um cenário no qual era debatida a possibilidade de erradicação da malária. Especialistas e dirigentes de instituições de saúde internacionais solicitavam esclarecimentos das pesquisas feitas pelos brasileiros. Isso posto, o sal cloroquinado passou a ser uma possível alternativa para superar as restrições técnicas e operacionais do uso do DDT, podendo viabilizar primeiro o controle e, posteriormente, a erradicação da doença (SILVA e HOCHMAN, 2010). Como forma de reconhecer a importância que o sal tinha adquirido para a saúde pública, o governo federal criou, em 1957, o Instituto Brasileiro do Sal (IBS), em substituição ao antigo Instituto Nacional do Sal. Uma das atribuições deste órgão era fomentar a fabricação do sal iodetado e do sal cloroquinado para consumo nas regiões atingidas pelo bócio endêmico e pela malária (BRASIL, 1957).

Após corresponder-se com Pinotti e conhecer melhor a metodologia de ação do novo medicamento, Emilio Pampana, malariologista e chefe da Divisão de Malária da Organização Mundial da Saúde, passou a considerá-lo um potencial complemento ao DDT ou uma alternativa em regiões onde a aplicação do inseticida era inviável. A ascensão do malariologista brasileiro coincidiu com uma mudança de prioridades do programa de saúde 
do então presidente da época, Juscelino Kubitschek, do qual Pinotti, em 1958, seria o ministro de saúde - além de colaborador no programa de saúde quando JK ainda era candidato. No programa de governo do então candidato JK, o Brasil não era mais visto como um imenso hospital, pois ele acreditava que melhorias relevantes tinham ocorrido com a erradicação da febre amarela e outras áreas da saúde pública brasileira (HOCHMAN, 2009; HOCHMAN, 2008). O futuro presidente colocou no topo de sua agenda sanitária o controle de doenças de endemias rurais, dando prosseguimento à tradição médica brasileira que, desde o início do século XX, preocupava-se em eliminar essas enfermidades. A malária, de acordo com o programa, poderia ser, em breve, banida do país graças ao trabalho persistente dos profissionais brasileiros (IDEM). Esta visão positiva sobre o controle da doença já tinha sido divulgada no período inicial da borrifação por DDT, nos anos 1940. Charles Wagley, antropólogo do Serviço Especial de Saúde Pública, afirmou em 1948 que o controle da malária já não constituía um problema sério para o desenvolvimento das regiões tropicais, como a Amazônia (WAGLEY, 1988). Até aquele momento, a sensação compartilhada pelos especialistas era de que bastava apenas borrifar para eliminar o mosquito e a doença.

Durante o mesmo período (maio de 1955), a OMS aprovava uma resolução para lançar no mundo um programa de erradicação da malária, que previa o fim da doença em um prazo estipulado. A própria organização sanitária panamericana também reforçaria esta proposta para os países-membros. Ao contrário do discurso de JK, o Brasil foi considerado um dos principais locais em que a campanha seria levada adiante, devido a uma tradição que o país já possuía em colaborações internacionais, como o trabalho realizado pela International Health Division da Fundação Rockefeller, entre 1939 e 1941. Três anos depois do lançamento da resolução da OMS, o Brasil também colocaria a erradicação da doença como uma de suas prioridades. Os fatores que propiciaram tais mudanças relacionam-se ao contexto internacional na política externa brasileira, em especial com o papel proeminente que os EUA ocuparam no programa de erradicação da malária. Com a necessidade de financiamento para os planos nacionais que visavam ao fim do subdesenvolvimento, JK deu prosseguimento ao histórico alinhamento nacional com os estadunidenses e lançou a Operação Pan Americana (OPA), em 1958, que partia da premissa de que os EUA financiariam programas que visavam ao fim do subdesenvolvimento latino americano. Em um contexto de Guerra Fria, os baixos índices apresentados pela América Latina poderiam resultar em um terreno fértil para o avanço do comunismo nestas regiões. O programa de erradicação também daria ao governo brasileiro a oportunidade de obter verbas internacionais as quais poderiam colaborar com os trabalhos dos médicos brasileiros, que poderiam terminar o trabalho iniciado na década de 1940 (HOCHMAN, 2008). 
O sal cloroquinado, já envolvido como um dos principais métodos que auxiliariam na erradicação da doença, continuou a ser discutido em artigos da época. De forma geral, mesmo identificando possíveis problemas, os profissionais estavam convencidos de que este seria a melhor forma de eliminar a malária do resto do país. Fernando Bustamante, então coordenador da Campanha de Erradicação da Malária (CEM) no Brasil, demonstrava otimismo sobre a erradicação da doença. Partilhando um discurso comum ao que temos apontado aqui, o sanitarista acreditava que o homem possuía técnica e conhecimento o suficiente para eliminar a enfermidade. Assim, a erradicação da malária era "tudo ou nada" (BUSTAMANTE, 1958, p.98). O sal cloroquinado seria, neste processo, um elemento fundamental para este processo, pois se relacionava a alimentação, tornando-se assim uma maneira mais prática e menos custosa de acabar com a doença. A erradicação da malária seria assim um problema muito mais financeiro e administrativo do que técnico, já que a maioria dos países que contavam com altos índices da enfermidade estavam entre os chamados subdesenvolvidos e muitos deles não possuíam condições técnicas, administrativas e financeiras para levar a cabo a tarefa de forma autônoma. Ele acreditava que, com a tecnologia disponível àquele momento, a erradicação da doença poderia acontecer em 30 anos (IDEM).

Em artigo escrito no ano seguinte Bustamante continuava otimista sobre o método Pinotti, porém já tecia algumas considerações sobre os possíveis problemas enfrentados na aplicação do produto. Um problema seria o custo, que ficaria mais elevado, porque parte do sal consumido não se destinava ao preparo de alimentos, mas à salga de peixes e carnes, por exemplo (BUSTAMANTE, 1959). Dessa forma, o tratamento total do sal ficaria mais encarecido. Em outras regiões, como o vale do Araguaia, no Pará, o sal grosso era preferido para a salga de carne, podendo assim, levar ao consumo de sal não tratado com o medicamento. Bustamante recomendava dessa forma a adoção de regras legais que proibissem a venda e consumo de sal grosso na região, embora soubesse que tais medidas poderiam ser mal recebidas, devido ao aumento de custo e, principalmente, por contrariarem hábitos tradicionais. Outro problema era o sal de mesa, consumido pelos habitantes das capitais, cuja entrada não era controlada. (IDEM) 


\section{Imagem 3:}

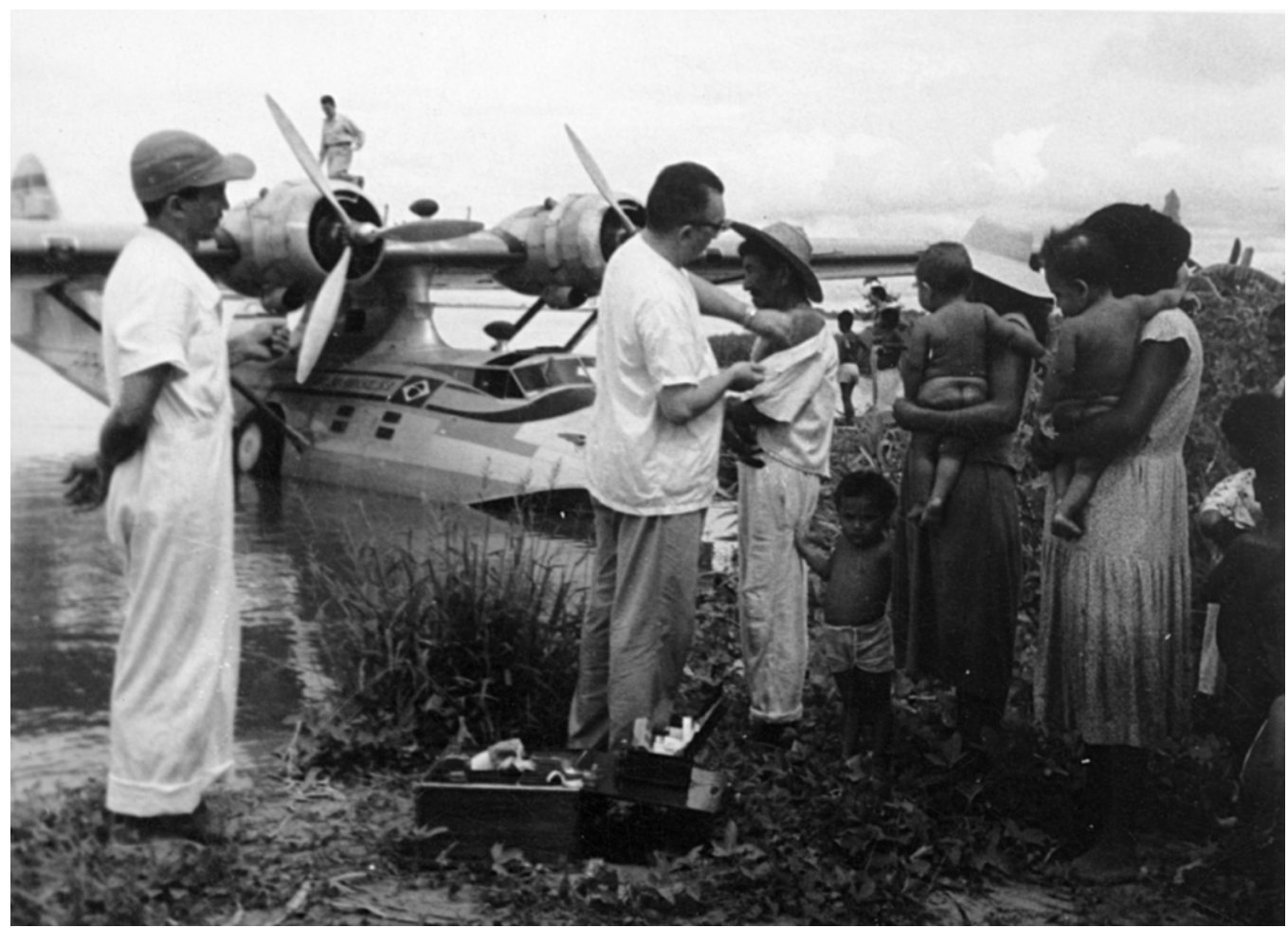

Inquérito Hemoscópico. Região amazônica [1952-1955].

Fundo Rostan Soares, fot.47.

\section{A queda do Sal Pinotti}

Em 1960, os primeiros problemas na adoção do sal cloroquinado foram detectados por profissionais ligados ao Departamento Nacional de Endemias Rurais (DNERU). O químico Ernest Paulini, por exemplo, foi solicitado pela OMS para instalar serviços de sal cloroquinado em regiões da Ásia e África, pois fora detectado que estas regiões tinham características semelhantes às encontradas na Amazônia brasileira (RACHOU, 1960). O método Pinotti foi utilizado inclusive no programa de erradicação da enfermidade na Guiana Inglesa. O próprio Paulini publicou artigo no qual apontava métodos de controle para o programa. Recomendava o controle periódico da presença do sal cloroquinado nas casas por meio da reação de iodo e exame de urina para detectar a cloroquina (PAULINI, 1960). Além disso, destacava que a estabilidade da reação entre o sal e a cloroquina só era possível em 
regiões de umidade baixa (80\%). Se passasse disso, haveria perda da droga e diminuição da uniformidade da mistura.

O também malariologista René Rachou reconhecia, em 1960, que o Método Pinotti ainda não estava "totalmente desenvolvido" para que se pudesse assegurar que era uma arma exclusiva e absoluta na erradicação da malária (RACHOU, 1960). Entre os obstáculos enfrentados para o uso extensivo do sal estavam a necessidade de assegurar que todo o sal consumido em uma determinada área malárica fosse consumido; o pequeno consumo de sal por certas populações, exigindo um aumento do teor da cloroquina no sal a ser distribuído e a alta solubilidade do disfosfato de cloroquina, fazia com que, em regiões de alta umidade, o sal moído ou triturado absorvesse grande quantidade de vapor d'água a ponto de dissolver a substância, diminuindo o teor da mistura. Por fim, havia o fato de que os lactentes não recebiam sal e as crianças de pouca idade ingeriam-no em pouca quantidade (IDEM). Rachou esperava que a importância deste grupo que não receberia o sal fosse pouca para a transmissão de malária.

Junto às críticas em relação ao sal, o criador do novo método também passava por um período de inferno político. No período das eleições presidenciais, Pinotti foi afastado do Ministério da Saúde por Juscelino Kubitschek devido a suas relações com o Partido Social Progressista (PSP) de Ademar de Barros e aos ajustes políticos que antecederam as eleições de outubro de 1960. Posteriormente, durante o governo Jânio Quadros, ele e seus colaboradores foram alvo de acusações e inquéritos. O médico então se retirou da vida pública para sempre. Durante o regime militar, seu inquérito foi arquivado por falta de provas (SILVA e HOCHMAN, 2011). Ao mesmo tempo, pesquisas científicas apontavam problemas no uso extensivo da cloroquina.

Em 1961, a OMS promoveu uma reunião técnica sobre quimioterapia na malária, na qual foi reconhecida a emergência de cepas de Plasmodium falciparum resistentes à cloroquina, representando assim, uma ameaça ao Programa de Erradicação de Malária (SÁ, 2011). Nos relatórios da OMS, também circulavam notícias sobre a resistência do Anopheles ao DDT. Após insistentes anúncios de casos de resistência à cloroquina e da inadequação das estratégias do programa em diversas regiões, (Tailândia, Colômbia, sul e sudeste asiático, bacia amazônica e vários países da África subtropical) ficou clara a necessidade de reavaliação dos protocolos e das ações de combate à doença (IDEM).

O esquecimento do Método Pinotti, em conjunto com as descontinuidades administrativas, foram simbólicos para o fracasso do Programa de Erradicação de Malária. Pelos planos, a erradicação completa deveria ocorrer em 1967. Na década de 1970, verificou-se que a crença no fim da doença era insustentável por razões epidemiológicas, 
econômicas, sociais e entomológicas que impediam a erradicação a longo prazo (SILVA, 2008)). A Campanha de Erradicação da Malária não obteve êxito na Amazônia, mas a transmissão da enfermidade foi interrompida nas regiões do Nordeste, Sudeste, CentroOeste e Sul. Retornando ao contexto nacional, críticas foram feitas na III Conferência Nacional de Saúde (CNS), em 1963, decretando definitivamente o fim do Método Pinotti como ferramenta para a erradicação da doença. Segundo o relatório, verificou-se, em 1961, que somente $51 \%$ das amostras recolhidas no comércio e em áreas urbanas e rurais continham cloroquina e que, somente $10,5 \%$ apresentaram concentração dentro da faixa considerada necessária à eficiência do produto (BRASIL, 1963). Ficou também evidente que os comércios locais provavelmente forneciam sal sem cloroquina, afetando o controle da substância. Outro problema era o gosto da cloroquina, que se tornava preponderante em relação ao sal (IDEM).

Em publicação contemporânea à III CNS, o médico Dante Costa defendeu o uso do sal cloroquinado. Segundo o nutrólogo, a alta mortalidade que a malária estava adquirindo era fruto de uma inversão: até 1962, o Plasmodium vivax, menos mortal, era o responsável pela maior parte dos casos da doença (COSTA, 1965). Posteriormente, 87\% dos casos passaram a ser provocados pelo Plasmodium falciparum, muito mais ativo e mortal, além do problema crescente da resistência do mosquito ao DDT (IDEM). Costa defendeu a continuação do Sal Pinotti, pois, segundo ele, o valor do método estava provado pelo não recrudescimento da doença entre 1959 e 1960, período em que, devido à falta de inseticida, o combate à malária ficou sob a responsabilidade exclusiva do sal cloroquinado, e as estatísticas não assinalaram avanço da doença (IDEM).

Os índices de malária ainda subiriam na década de 1960 por conta da principal intervenção estatal do período na região amazônica: a rodovia Belém-BrasíBrasílialia. Durante a presidência de João Goulart (1962-1964), o médico Amilcar Martins foi destacado pela agência para fazer um relatório sobre a enfermidade, provavelmente entre os anos de 1961 e 1962, e teceu diversas críticas ao uso extensivo e, segundo ele, "sem controle" do sal (SILVA, 1964, p.17). Entre as razões para os novos surtos, estavam o constante deslocamento de pessoas pelos vilarejos surgidos ao longo da estrada, que, de tempos em tempos, abandonavam os antigos povoados para se deslocarem para as áreas mais férteis. Predominava, nessas regiões, a forma clínica "terçã-maligna", produzida pelo Plasmodium falciparum, de extrema virulência (IDEM). Os sintomas apareciam subitamente, às vezes com aspecto de enfermidade desconhecida e frequentemente mortal. Como a propagação era rápida, existiam áreas onde praticamente a totalidade da população era atingida. 
Nas regiões submetidas ao longo dos anos ao regime do sal cloroquinado surgiram, além das raças de plasmódios cloroquino-resistentes, formas clínicas atípicas, com lesões orgânicas muito graves, mascaradas com sintomatologia de meningite, hepatite, pneumonia, doenças renais ou cardiovasculares, psicoses e, às vezes, coma. Esses fatos alarmaram as populações, dando-lhes a impressão de se acharem em presença de uma nova entidade mórbida, desconhecida e, nas palavras do médico, "maligna e mortal" (IDEM). Outra crítica, que encontra eco em outras avaliações sobre o uso do sal, é a falta de conhecimento sobre os costumes locais. Segundo Amílcar Silva, mesmo que todo o sal distribuído contivesse rigorosamente igual dose de cloroquina (segundo ele, impossível na prática), nem todos os habitantes ingeriam os alimentos com a mesma quantidade de sal, sendo que alguns nem utilizavam o tempero na alimentação. Dessa forma, existia a possibilidade de os parasitas resistirem no sangue das pessoas e, quando fossem passados para os mosquitos, surgiria assim um mutante de plasmódio, resistente à cloroquina (IDEM).

Este fato demonstra também a falta de coordenação e comunicação entre as diversas esferas governamentais. Na década de 1950 e início dos anos 1960, diversas agências realizaram inquéritos locais, com o objetivo de pesquisar o valor nutritivo da dieta local, bem como mapear os hábitos alimentares da população da Amazônia.1 Em muitos dos relatórios frutos destas excursões, era destacado o fato de que os amazônidas, de forma geral, ingeriam pouco sal. Ou, como os relatórios do Sérvio Nacional de Malária demonstraram, havia a rejeição dos habitantes ao sabor do sal medicamentoso. Como a cloroquina é bastante solúvel em água, ela se depositava no fundo do saco em zonas muito úmidas. Com isso, a população ingeria uma quantidade inadequada nas partes superficiais e quando chegava ao final, o sal ficava muito amargo (TAUIL et ali, 1985). Essa característica do sal tornava amargo alimentos tradicionais da região, como o pirarucu e a carne salgada para a secagem no sol (GUSMÃO, 1991). Não era um produto comum na mesa dos habitantes, em especial devido à dificuldade de abastecimento do tempero para a Amazônia, cuja distribuição concentrava-se em poucas regiões, principalmente nas capitais, transformando o comércio do sal em algo difícil, dependente de fornecedores locais, que viajavam por estradas ruins e, em muitos casos, dependiam do transporte pelos rios locais. Outras conseqüências do desequilíbrio de concentração entre a cloroquina e o sal foram as queixas dos habitantes de náuseas, vômitos e diarréias (GUSMÃO, 1991).

A falta de informação às pessoas deu origem a anedotas sobre o sal medicamentoso. Jarbas Passarinho, superintendente da Petrobras na Amazônia entre 1958 e 1959, afirmou em depoimento que o sal cloroquinado era utilizado no controle de malária nos técnicos que estavam trabalhando na região. Certo dia, vários funcionários reclamaram de febres, e, após inspeção médica, confirmou-se que tratava-se de um surto de malária. Descobriram então 
que o sal cloroquinado fora substituído pelo sal comum na venda local. Inquirido, o chefe da equipe teria dito ao médico responsável que todos haviam se negado a continuar ingerindo o tal sal porque corria um forte boato de que provocava impotência sexual (PASSARINHO, 2012). A falta de conhecimento sobre a cultura local dava a o tom dos trabalhos de controle de malária, mesmo nos anos subsequentes, lançando estigmas sobre a população local. Em relatório da Campanha de Erradicação da Malária, de 1965, do setor Roraima, então um território pertencente à circunscrição da SPVEA, os técnicos apontavam suas opiniões sobre os indígenas:

\begin{abstract}
Os índios são e serão ainda por muito tempo um dos fatores mais decisivos na persistência da transmissão [da malária]. (...) Além de não ingerirem as drogas, quando o fazem é a troco de terçados, machados, etc. e só ingerem uma dose, internando-se no mano onde não mais podemos alcançá-los. No rio Apiaú, reside a nossa maior área-problema (...) eles descem aos grupos de 40 a 50 índios, se aproximam de uma habitação, ali ficam a 8 dias e se retiram quando nem sequer chegamos a medicá-los. Como quase todos são portadores de malária, já introduziram a mesma em todos os habitantes das casas sem paredes e se retiram deixando um grupo de moradores infectados. (...) Não temos lei como na Guiana Britânica, onde é obrigatório o uso do sal cloroquinado e a retirada de lâminas do sangue e ingestão do comprimido de cloroquina. (BRASIL, 1965, p.30)
\end{abstract}

Um triste réquiem para o sonho de erradicação foi o surto de malária ocorrido nos vilarejos da llha de Marajó, no Pará, em 1966. Em 16 de outubro , o Jornal do Brasil noticiava que mais de duas mil pessoas tinham morrido em poucos dias em consequência da doença que, segundo o jornal, ameaçava dizimar os 25 mil habitantes da ilha. Pracuúbua, um pequeno vilarejo de 400 habitantes, estava ocupada somente por animais domésticos, muitos dos quais tinham se retirado para o campo, fugindo do mau cheiro que dominava a cidade, onde numerosos cadáveres permaneciam insepultos. Os cinco cemitérios da ilha estavam inteiramente lotados. A população de Muana reunia-se todos os dias diante da igreja e rezava, pedindo a ajuda de Deus contra a malária, pois a ilha não contava sequer com um posto de saúde, farmácia ou médico. A CEM não tinha tomado qualquer providência e, de acordo com o jornal, Salomão Atias, o superintendente, procurou esconder a gravidade da situação, desmentindo os fatos. A reportagem destacava que a cena mais vista era dos barracos com apenas os cachorros e os papagaios, porque os membros da família estavam mortos dentro das casas. A maior parte das vítimas era constituída de crianças até sete anos de idade, sendo que parte dos doentes encontrava-se na fase aguda, e, segundo a reportagem, expelindo sangue por todas as partes do corpo. A Igreja de Muana tinha 
deixado de repicar os sinos em sinal de protesto contra o abandono que as populações da Ilha ficaram relegados.1

A malária, após as experiências de erradicação das décadas de 1950 e 1960, teve sua incidência bastante reduzida, chegando a diminuir para 52.000 casos em 1970. Porém nas décadas seguintes, a doença cresceu de forma exponencial: nos anos 1980, foram registrados 170.000 casos. Já em 1999, cerca de 600.000 casos de malária, quase que exclusivamente na região amazônica, foram relatados. Packard (2007) relaciona o aumento vertiginoso dos casos da doença às políticas de desenvolvimento agrícola empreendidas pelo Estado brasileiro neste período. As incursões humanas nas florestas, construção de estradas como a Belém-Brasília (1958) e a Transamazônica (1970) tiveram como conseqüência um enorme fluxo populacional em busca de terras prometidas pelos governos do período. Somente em Rondônia, cerca de um milhão de imigrantes chegaram entre as décadas de 1970 e 1980 (PACKARD, 2007). Entre as razões para o aumento da transmissão de malária entre os novos imigrantes estava o fato de a enfermidade ter sido eliminada do restante do país. Assim, muitas das pessoas que se mudaram para a Amazônia não possuíam imunidade à doença. Além disso, existia o fator ecológico: muitos dos animais que eram picados pelo Anopheles Darlingi foram expulsos pelo desmatamento que caracterizou muitos desses programas de imigração dirigida. Dessa forma, os mosquitos se alimentaram basicamente de hospedeiros humanos (IDEM).

O sal cloroquinado ainda seria utilizado por um longo período na região da Serra do Navio, no território do Amapá, região estratégica para extração de manganês, explorado pela Indústria de Minério e Comércios S.A. (ICOMI). O programa foi iniciado em 1960 e concluído em 1984 entre os funcionários da empresa que residiam por lá. De acordo com Hermelino Galvão, um dos responsáveis pelas ações de combate à malária no território do Amapá, entre 1961 e 1974, a divisão local de saúde obteve a cura de todos os casos de ataques agudos de malária, mesmo nas incidências mais "tolerantes" aos tratamentos, com nenhuma fatalidade entre os pacientes. Diferente de outras regiões da Amazônia, o uso do sal entre os trabalhadores da ICOMI e residentes na serra do navio obteve êxito, muito em função da estratégia desenvolvida pela Divisão de Saúde local. Como a empresa fornecia o sal para os funcionários, existia um controle mais rígido em relação à dosagem de cloroquina, além de constantes exames de urina e de sangue nos funcionários. Um aspecto que diferenciou a ação no Amapá das outras foi a elaboração e implementação de um programa de educação sanitária, com o objetivo de informar e orientar a comunidade local sobre os objetivos e os benefícios esperados da aceitação do uso do sal cloroquinado no preparo da alimentação (GALVÃO, 1991). O sucesso foi tanto que, em 1966, 100\% das amostras de urina examinadas continham cloroquina, coroando o êxito do trabalho. Segundo o malariologista, 
o método foi sumariamente abandonado em outras regiões sem que se fizesse um esforço, bem planejado e rigorosamente executado para provar sua eficácia (IDEM). Os diretores da empresa, à época da implantação do programa, tinham muitas dúvidas sobre a aceitação do sal, pois além de ser uma interferência na alimentação, já era notória a rejeição que o método sofreu de diversos grupos populacionais da própria região amazônica. Resistências ocorreram, mas, de acordo com Galvão, foram superadas pelo trabalho de educação sanitária e, principalmente, pela acentuada queda dos casos de malária. A eclosão do garimpo na década de 1980 foi responsável pela reincidência de casos de malária, contando, devido a imigração, com diversos casos de óbitos entre os homens que foram para lá. A epidemia chegou a graus tão extremos que, em 1982, foi observado pelos médicos da ICOMI um agravamento das condições clínicas dos pacientes, contando inclusive com manifestações neurológicas em decorrência da malária.

\section{Considerações finais}

O historiador John Farley, ao analisar as concepções presentes na agenda da saúde internacional no período pós-Segunda Guerra Mundial, concluiu que os esforços para melhorar a saúde e o bem-estar econômico poderiam ser visualizados em pêndulos fixos em dois extremos. No campo da saúde, dois pêndulos seriam os principais: o primeiro balançava entre a concepção de que o controle ou erradicação de doenças transmissíveis seria um prérequisito para o desenvolvimento socioeconômico e a noção de que o desenvolvimento socioeconômico seria um pré-requisito para a melhoria da saúde. $O$ segundo pêndulo estaria entre aqueles que acreditavam que as campanhas poderiam ser direcionadas verticalmente contra doenças específicas e que seriam impostas de "fora" e aqueles que argumentavam que as campanhas contra doenças transmissíveis necessitavam ser feitas de formas horizontal e envolviam um mínimo de infraestrutura de saúde pública e que as campanhas não poderiam ser impostas, de "cima" para "baixo" (FARLEY, 2004). Uma campanha vertical como foi a do sal cloroquinado expõe de forma clara os limites destas concepções. Randall Packard (2007) destaca que, ao analisar a história do combate à malária, é fundamental perceber a necessidade de junção entre ferramentas médicas e melhoria das condições sociais e econômicas relacionadas à epidemiologia da doença.

Sobre o Método Pinotti, É importante destacar que o programa praticamente ignorou todo o esforço empreendido pelos técnicos e nutrólogos em compreender os hábitos alimentares dos homens da Amazônia. Não encontramos nos artigos que defendiam o uso extensivo do sal cloroquinado citações ou conexões com o material produzido pelos 
técnicos e pesquisadores da nutrição brasileira. Essa experiência serve de reflexão para pensar os limites de um programa vertical que ignorou pesquisas, inquéritos e uma certa narrativa existente sobre os hábitos alimentares dos homens da Amazônia.

\section{REFERÊNCIAS BIBLIOGRÁFICAS}

ANHEL, Ramon Affonso. Aplicação e controle do sal cloroquinado nas localidades de Guarapiranga e Arajacají, Inquéritos hemoscópicos realizados antes e depois da aplicação, no período de 14/04/1953 a 19/6/1953. São Luís, 18/07/1953. Arquivo Casa de Oswaldo Cruz. Fundo Rostan Soares, caixa 73, 19520124

BATISTA, Djalma. O Complexo da Amazônia - (Análise do Processo de Desenvolvimento). Rio de Janeiro: Editora Conquista, 1976.

BRASIL. LEI No 3.137, DE 13 DE MAIO DE 1957. Disponível em: <http://www.planalto.gov.br/CCIVIL 03/LEIS/1950-1969/L3137.htm>. Acesso em: $11 / 06 / 2012$

BRASIL. Campanha de Erradicação da Malária - Setor Roraima - Relatório Especial - 1965. Roraima, 1965

BRASIL. Anais da III Conferência Nacional de Saúde. Brasília, 1963

BRASIL. Primeiro Plano Quinquenal, SPVEA - Setor de Coordenação e Divulgação, 1955.

BIZELLO, Maria Leandra. Imagens Otimistas: Representações do desenvolvimentismo nos documentários de Jean Manzon. Dissertação apresentada ao curso de Mestrado em Multimeios do Instituto de Artes da UNICAMP. Campinas, 1995

BUSTAMANTE, Fernando Machado. Considerações sobre certos problemas especiais relacionados com a erradicação de malária no Brasil. Revista Brasileira de Malariologia e Doenças Tropicais.V. XI, n. 1, janeiro, 1959

BUSTAMANTE, Fernando Machado. Estado Atual do Problema de Malária. Revista Brasileira de Malariologia e Doenças Tropicais. V. X, n. 1, jan. 1958

CIVES. Centro de Informação em Saúde para Viajantes, 2012. Disponível em: <http://www.cives.ufrj.br/informacao/malaria/mal-iv.html>, Acesso em: 11/06/2012

COSTA, Dante. Saúde, Alimentação e Pobreza na Amazônia. Rio de Janeiro: Ministério da Educação e Cultura, 1965 
DAMSCENO, R. M. G. Programa de Sal Cloroquinado no Pará. 1953-1953. Arquivo Casa de Oswaldo Cruz. Fundo Rostan Soares, caixa 73, 19520124

DUNN, Frederick L. Malaria. In: Kiple, Frederick. The Cambridge Historical Dictionary of Disease. United Kingdom: Cambridge University Press, 2003

FARLEY, John. To Cast Out Disease: a history of the international Health Division of the Rockefeller Foundation (1913-1951). Oxford, Oxford University Press: 2004

GUSMÃO, Hermelino Herbster; JUAREZ, Edmundo. O programa de malária: uso do sal cloroquinado, a longo prazo, como agente supressivo. GUSMÃO, Hermelino Herbster. Programa de saúde integrado ao complexo da infra-estrutura social: 25 anos na Amazônia; 1961-1985. s.I, Universidade de Säo Paulo. Faculdade de Saúde Pública, 1991. pp.133-77.

HOCHMAN, Gilberto. O Sal como solução? Políticas de saúde e endemias rurais no Brasil (1940-1960). Sociologias, Porto Alegre, ano 12, n. 24, mai. 2010

HOCHMAN, Gilberto. O Brasil não é só doença: o programa de saúde pública de Juscelino Kubitschek. História, Ciências, Saúde - Manguinhos, v. 15, supl.1, jul. 2009.

HOCHMAN, Gilberto. From Autonomy to Partial Alignment: National Malaria Programs in the Time of Global Eradication. Brazil. CBMH/BCHM, v. 25, n. 1, 2008

MANZON, Jean. Malária no Inferno Verde. Rio de Janeiro, Jean Manzon Films, 1954. Disponível em: <www.acervojeanmanzon.com.br>. Acesso em: 11/06/2012

PASSARINHO, Jarbas. Depoimento concedido ao sítio "Ninho da Natureza" - O Petróleo da Amazônia, de Eliezer de Oliveira Martins. Disponível em: <http://www.eliezer.ninhodanatureza.nom.br/02/04/index.htm>. Acesso em: 20/06/2012

PAULINI, Ernest. Further Studies on Chloroquinized table salt. Revista Brasileira de Malariologia e Doenças Tropicais, v. XII, n. 2, abr. 1960

PINOTTI, Mario. LÔBO, Ary G.S., DAMSCENO, G., SOARES, Rostan. Experiências de campo com o sal cloroquinado. Revista Brasileira de Malariologia e Doenças Tropicais. V. VII, n. 1, Janeiro de 1955

PINOTTI, Mario. Um novo Método de Profilaxia da Malária: Associação de uma droga antimalárica ao sal de cozinha usado na alimentação diária. Revista Brasileira de Malariologia e Doenças Tropicais. Rio de Janeiro, v.VI, janeiro de 1954, n.1, p. 5.

RACHOU, René G. O Método Pinotti nas Atuais Campanhas de combate à Malária. Revista Brasileira de Malariologia e Doenças Tropicais, v. XII, n. 2, abr. 1960 
SÁ, Ivone Manzali de. A resistência à cloroquina e a busca de antimalariais entre as décadas de 1960 e 1980. História, Ciências, Saúde - Manguinhos, 18 (2), 2011, p. 407-430

SCHWEICKARDT, Julio Cesar. Ciência, nação e região: as doenças tropicais e o saneamento no Estado do Amazonas (1890-1930). Tese (Doutorado Programa de Pós-Graduação em História das Ciências e da Saúde) - Fiocruz/Casa de Oswaldo Cruz, 2009.

SECRETO, Maria Verônica. A ocupação dos "espaços vazios" no governo Vargas: do "discurso do Rio Amazonas" à saga dos soldados da borracha. Estudos Históricos, n. 40, jul-dez. 2007

SILVA, Renato da; HOCHMAN, Gilberto. Um método chamado Pinotti: sal medicamentoso, malária e saúde internacional (1952-1960). Hist. cienc. saude-Manguinhos, Rio de Janeiro, v. 18, n. 2, June. 2011

SILVA, Renato. Malária e Desenvolvimento: a Saúde Pública no governo JK (1956-1961). Tese de doutorado apresentada ao Programa de Pós Graduação em História das Ciências e da Saúde, Casa de Oswaldo Cruz-Fiocruz, Rio de Janeiro, 2008

SILVA, Amílcar Martins. Modernos Conceitos sobre Malária. Rio de Janeiro, SPVEA

SNM. Relatório do Rio Capim, Arquivo Casa de Oswaldo Cruz. Fundo Rostan Soares, caixa 73, 19520124, 1952

TAUIL, Pedro; DEANE, Leônidas; SABROZA, Paulo; RIBEIRO, Cláudio. A malária no Brasil. Cadernos de Saúde Pública, 1(1), p. 71-111, 1985.

WAGLEY, Charles. Uma Comunidade Amazônica - estudo do homem nos trópicos. Belo Horizonte: Editora Itatiaia, 1988. 